\title{
Prepubertal/Pediatrik Akne
}

Öz

Pilosebase foliküllerin kronik enflamatuvar bir hastalığı olan akne özellikle ergenlik yaşlarındaki çocuklarda sıktır ancak yenidoğan, bebeklik, erken çocukluk, puberte öncesi ve sonrası dönem dahil çocukluğun her döneminde görülebilir. Yenidoğan döneminde daha hafif seyirli ve kolay gerileyen lezyonların yanı sıra çocuklarda da skar oluşumuna neden olacak kadar şiddetli seyir gösteren tablolar görülebilir. Bu yazıda doğumdan 12 yaşına kadar görülen akne formlarından bahsedilmiştir.

Anahtar Kelimeler: Pediatrik akne, çocukluk aknesi, yenidoğan aknesi

\section{Abstract}

Being a chronic disease of the pilosebaceus follicles, acne is common particularly in children in adolescence, but can also be seen in all periods of childhood including neonatal period, infancy, early childhood, pre- and post-puberty. The lesions have a mild course and can easily recover in the neonatal period, but conditions so severely progressing to cause scars can also be seen in children. This paper deals with acne forms seen in children from birth through 12 years of age.

Keywords: Pediatric acne, childhood acne, neonatal acne

\section{Giriş}

Akne ergenlik yaşlarındaki çocuklarda sık olsa da yenidoğan, bebeklik, erken çocukluk, puberte öncesi dönem dahil çocukluğun her döneminde görülebilir. Yenidoğan döneminde daha hafif seyirli ve kolay gerileyen lezyonların yanı sıra skar oluşumuna neden olacak kadar şiddetli seyir gösterebilmektedir ${ }^{1-7}$. Pediatrik akne alt tipleri Tablo 1'de görülmektedir ${ }^{2,3}$.

\section{Neonatal Akne}

Yenidoğanların yaklaşık \%20'sinde, doğumda veya sıklıkla 4.-6. haftalar arasında, tipik olarak alın, burun ve yanaklarda yerleşmiş hafif eritematöz papülopüstüller şeklinde görülmektedir, boyun ve gövdeye de yayılabilir (Şekil 1). Komedonlar nadirdir (Tablo 2). Erkek çocuklarda daha sıktır 1,2,5.

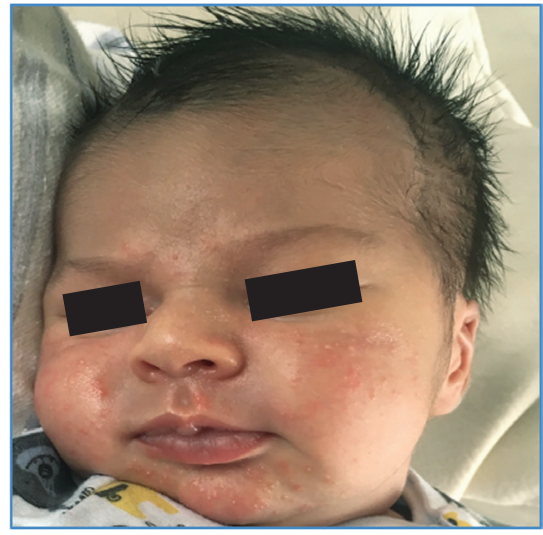

Şekil 1. Neonatal akne. Alın, yanaklar ve çenede minik papülopüstüler lezyonlar, az sayıda komedonal lezyonlar

Yazıșma Adresi/Address for Correspondence: Prof. Dr. Serap Utaş

Fulya Acıbadem Hastanesi, Deri ve Zührevi Hastallklar Anabilim Dalı, İstanbul, Türkiye

E-posta: seraputas@gmail.com ORCID: orcid.org/0000-0002-5298-7367

(C) Telif Hakkı 2020 Deri ve Zührevi Hastalıklar Derneği

Türkderm - Türk Deri Hastalıkları ve Frengi Arșivi, Galenos Yayınevi tarafından basılmıștı. 
Neonatal akne etiyolojisinde, genişlemiş sebase bezlerden sebum salgııının artışı suçlanmaktadır. Fetal adrenal organlar tarafından fazlaca dihidroepiandrosteron (DHEA) yapımı, trans plasental androjen hormonların geçişi ve testislerde hormon yapımı sorumlu tutulmaktadır. Testiküler androjen yapımı adrenal bezler içinde bir uyarı olup hastalığın erkek yeni doğanlarda neden fazla görüldüğünü de açıklayabilir'. illk aylardaki artmış sebum sekresyonu 6. ay civarında bazal seviyelerine döner ${ }^{6}$.

Akneli bebekleri muayene ederken lezyonların tipi ve dağııımı dışında boy, kilo, büyüme eğrileri, kan basınçları, seksüel matürasyon veya virilizasyon belirtilerine de dikkat edilmelidir ${ }^{3}$. Neonatal jinekomastinin normal bir varyant olduğu akılda tutulmalıdır. Şiddetli akne ile birlikte erken seksüel gelişme belirtileri, virilizasyonu ve büyüme anormalliği olan infantlar, altta yatan endokrin hastalık, tümör veya gonadal/ overyal patolojiyi ortaya çıkarmak açısından pediatrik endokrinoloğa yönlendirilmelidir ${ }^{3}$.

Neonatal akne genellikle 3-6 ay içerisinde kendiliğinden geriler. Nadiren daha uzun devam edebilir. Hafif olgularda yumuşak bir sabunla günlük yıkama yeterlidir. Dışarıdan uygulanan bebek yağı, krem, pomad ve losyonlardan tabloyu alevlendirebileceği için kaçınılmalıdır. Enflamatuvar lezyonları olan bebeklerde düşük konsantrasyonda benzoil peroksit (BPO) jel veya topikal antibiyotik önerilmektedir¹. Komedonal lezyonlar için BPO ile kombine veya tek başına topikal retinoid yeterlidir².

Yenidoğanlarda daha çok püstüler lezyonların görüldüğü tablo neonatal sefalik püstülozis olarak adlandırılır. Genellikle yaşamın ilk haftalarında görülen bu tablo yenidoğanların yaklaşık \%20'sinde görülmektedir, yüzde çok sayıda eritematöz papül ve püstül bulunur, nadiren saçlı deri, boyun ve göğüs üst kısımlarına yayılabilir (Şekil 2). Komedonların olmaması tanı açısından önemlidir ${ }^{1,2}$.

\section{İnfantil Akne}

Infantil akne 1-12 ay arasındaki bebeklerde görülür (Tablo 3). Erkek çocuklarda daha sıktır. Lezyonlar daha çok açık ve kapalı komedonlardır (Şekil 3), fakat enflamatuvar papül ve püstül, nodül ve kistler görülebilir (Şekil 4). Lezyonlar sıklıkla yüzde yerleşmiştir, ama boyun, sırt ve göğüste de bulunabilir. Hastaların \%80 kadarında infantil akne hafif ve orta şiddette seyir izler ve 1-2 yaşına kadar kendiliğinden geçer. Ancak

\section{Tablo 1. Pediatrik aknenin yaşlara göre}

\section{sınıflandırılması ${ }^{(2,3)}$}

\begin{tabular}{|l|l|l|l|l|}
\multicolumn{2}{|l|}{ Pediatrik akne } & $\begin{array}{l}\text { Adölesan } \\
\text { akne }\end{array}$ \\
\hline 0-6 hafta & $1-12$ ay & $1-7$ yaş & 7-12 yaş & $12-18$ yaş \\
\hline $\begin{array}{l}\text { Neonatal } \\
\text { akne }\end{array}$ & $\begin{array}{l}\text { Infantil } \\
\text { akne }\end{array}$ & $\begin{array}{l}\text { Orta çocukluk } \\
\text { aknesi }\end{array}$ & $\begin{array}{l}\text { Preadölesan } \\
\text { akne }\end{array}$ & $\begin{array}{l}\text { Adölesan } \\
\text { akne }\end{array}$ \\
\hline
\end{tabular}

\section{Tablo 2. Neonatal akne}

\begin{tabular}{|l|l|}
\hline Başlangıç yaşı & In utero-6 hafta \\
\hline Morfoloji & $\begin{array}{l}\text { Komedonlar, enflamatuvar papül ve püstüller, } \\
\text { nodül/kistler, skar }\end{array}$ \\
\hline \multirow{2}{*}{ Yayılım } & $\begin{array}{l}\text { Alın, yanaklar, burun, daha nadir olarak boyun ve } \\
\text { gövde }\end{array}$ \\
\hline \multirow{3}{*}{ Klinik ipuçları } & Kendiliğinden gerileme eğiliminde \\
\cline { 2 - 2 } & Topikal retinoidler yararlı olabilir \\
\cline { 2 - 2 } & Lezyonlar kalıcı ise veya skar bırakıyorsa araştırılmalı \\
\hline
\end{tabular}

yıllarca devam eden ve önceden tahmin edilemeyen, aktif lezyonların yıllarca sürdüğü bir seyir de izleyebilir2 ${ }^{2}$ Skar bırakabilir ${ }^{1,2}$.

Infantil akne de artmış androjen seviyeleri ile ilişkilidir. Hiperandrojenizm açısından taranmalıdır. Hormonal bozukluk düşünülüyorsa pediatrik endokrinoloğa yönlendirilmelidir. Hızı başlayan infantil aknede virilizan tümörleri dışlamak gereklidir ${ }^{2,5}$.

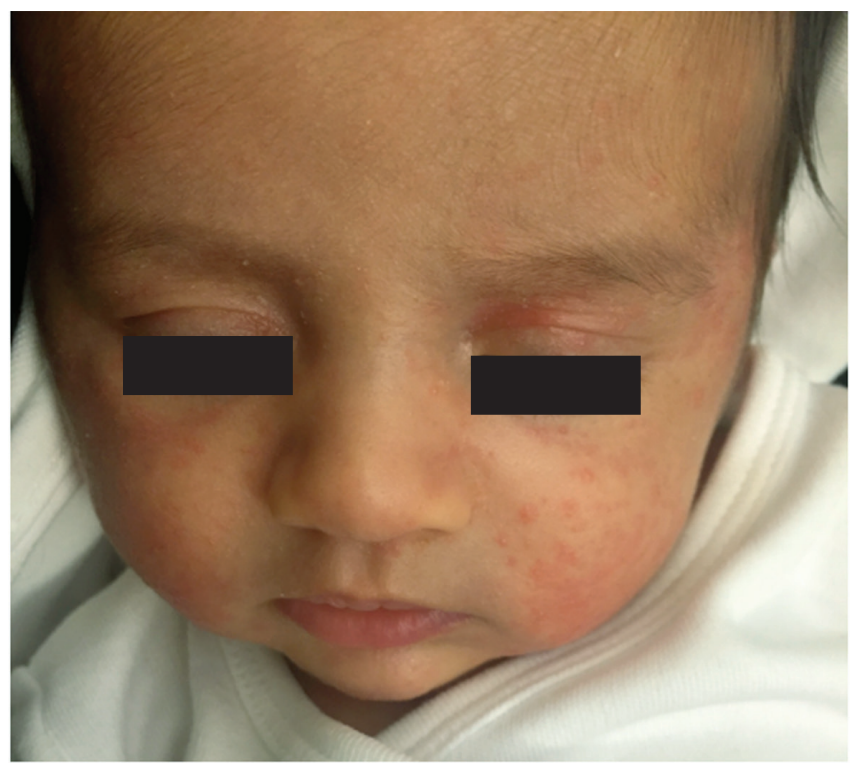

Şekil 2. Neonatal sefalik püstülozis. Yanaklarda papülopüstüler lezyonlar

\begin{tabular}{|c|c|}
\hline Başlangıç yaşı & 6 hafta-1 yıl \\
\hline Morfoloji & $\begin{array}{l}\text { Komedonlar, enflamatuvar papül ve püstüller, } \\
\text { nodül/kistler, skar }\end{array}$ \\
\hline Yayılım & Yüz özellikle yanaklar, göğüs ve sırt \\
\hline \multirow[t]{3}{*}{ Klinik ipuçları } & $\begin{array}{l}\text { Testiküler büyüme veya pubik kıllanma erken } \\
\text { puberte belirtisi }\end{array}$ \\
\hline & Skar oluşumu izotretinoin tedavisi gerektirebilir \\
\hline & Daha şiddetli adölesan akne göstergesi olabilir \\
\hline
\end{tabular}

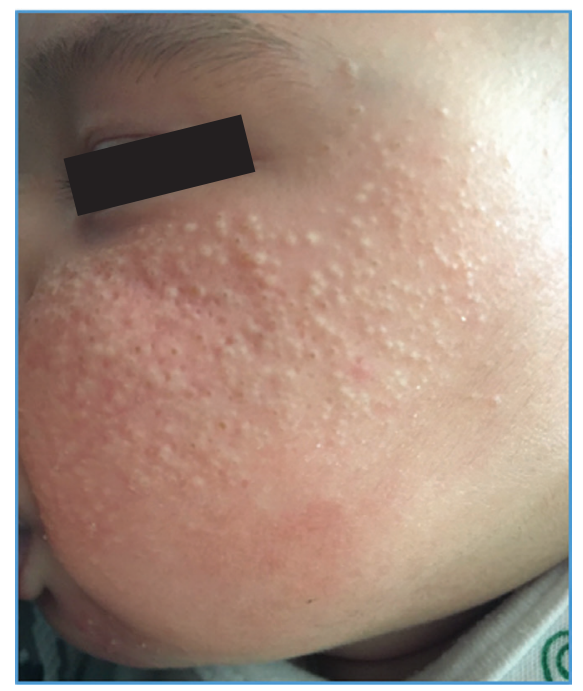

Şekil 3. Infantil akne, yanaklarda çok sayıda açık ve kapalı komedonlar 


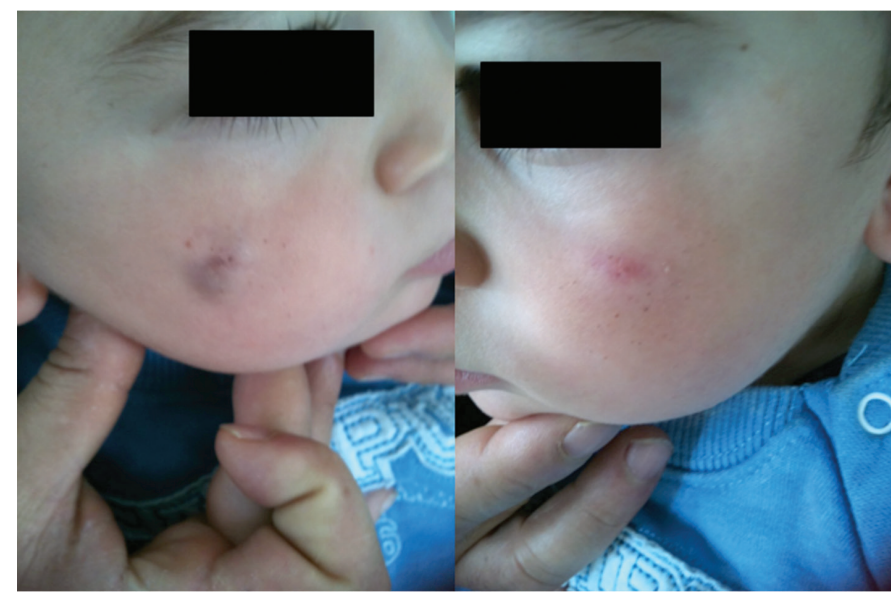

Şekil 4. Infantil akne. Yanaklarda papülonodüler lezyonlar

\section{Tablo 4. Orta çocukluk aknesi}

\begin{tabular}{|l|l|}
\hline $\begin{array}{l}\text { Başlangıç } \\
\text { yaşı }\end{array}$ & $\mathbf{1 - 7}$ yaş \\
\hline Morfoloji & Komedonlar, enflamatuvar papül ve püstüller \\
\hline Yayılım & Yüz, göğüs, sırt \\
\hline $\begin{array}{l}\text { Klinik } \\
\text { ipuçları }\end{array}$ & Bu yaş grubunda akne nadirdir \\
\cline { 2 - 2 } & Büyüme tablosu hastanın değerlendirilmesinde önemli \\
\cline { 2 - 2 } & Hiperandrojenik durumun habercisi olabilir! \\
\hline Hızlı değerlendirme ve pediatrik endokrin uzmanına yönlendirme
\end{tabular}

\section{Tablo 5. Hiperandrojenizm açısından klinik ve laboratuvar değerlendirme}

\begin{tabular}{l} 
- Aile öyküsü \\
\hline - ilaç maruziyeti \\
\hline - Aksiler, genital kıllanma ve koku \\
\hline - Meme ve testiküler gelişimin değerlendirilmesi \\
- Laboratuvar incelemeler: Serbest ve total testosteron, DHEA-S, \\
LH, FSH, Prolaktin, 17-hidroksiprogesteron, kemik yaşı için radyolojik \\
inceleme
\end{tabular}

DHEA: Dihidroepiandrosteron, LH: Luteinizan hormon, FSH: Folikül uyarıcı hormon

\section{Tablo 6. Preadölesan akne}

\begin{tabular}{|l|l|}
\hline Başlangıç yaşı & 7-12 yaş \\
\hline Morfoloji & $\begin{array}{l}\text { Komedonlar, enflamatuvar papül ve püstüller, } \\
\text { nodül/kistler }\end{array}$ \\
\hline Yayılım & $\begin{array}{l}\text { Yüz, özellikle alın, kulak konkaları etkilenebilir, } \\
\text { göğus ve sırt }\end{array}$ \\
\hline Klinik ipuçları & Puberte yaşı düştükçe insidansı artıyor \\
\hline $\begin{array}{l}\text { Altta yatan polikistikover veya geç konjenital adrenal hiperplazi gibi } \\
\text { olasılıklar düşünülmeli }\end{array}$ \\
\hline Tedavi adölesan ve erişkin akne tedavisine benzer şekilde \\
\hline
\end{tabular}

Infantil akne, skar oluşumunun önlenmesi için tedavi edilmelidir. Hafif ve orta şiddetteki hastalarda topikal BPO-antibiyotik kombinasyonları ve/veya retinoidler kullanılabilir. Bu tedavilere cevap alınamazsa oral azitromisin veya trimethoprim-sülfametoksazol kullanılabilir1,6. Tetrasiklinlerden bu yaş grubunda dişlerde kalıcı boyanmaya neden olacağı için kaçınılmalıdır2,6. Nodül ve skarlarla seyreden dirençli hastalar oral izotretinoin tedavisi açısından değerlendirilmelidir ${ }^{1,2}$. İzotretinoin kapsül, ışıkta stabil olmadığı için loş ışıkta açılıp uygun doz bir çorba kaşığı ılık süt içerisine konarak veya şekerli bir bar ile karıştırılıp dondurularak günlük iki bölünmüş dozda verilebilir2,5. Önerilen doz 0,2$1 \mathrm{mg} / \mathrm{kg} /$ gün olup 4-14 ay süresince kullanılmalıdır ${ }^{4}$. Hastaların yakın klinik ve laboratuvar değerlendirmeleri ergen ve erişkin hastalardakine benzer şekilde yapılmalıdır². Büyük nodüllere intralezyoner steroid enjeksiyonu $(2,5 \mathrm{mg} / \mathrm{mL})$ yapılabilir ${ }^{1,2}$.

\section{Orta Çocukluk Aknesi}

Aknenin en nadir görülen, ama görüldüğünde alarm nedeni olan orta çocukluk aknesi, 1-7 yaşları arasındaki çocuklarda görülür (Tablo 4). Özellikle yüze yerleşmiş komedonlar ve enflamatuvar lezyonlarla seyreder 2,3,5. Adrenal hormon sekresyonları yaşamın ilk yılının sonunda kesilir ve 6-8 yaşlarına kadar durgun kalı²,6. Bu nedenle bu yaşlarda akne görüldüğünde endokrin bir anormallikten şüphelenilmelidir. Pediatrik endokrinolog tarafından adrenal, gonadal veya overyal patolojiler (adrenal tümörler, konjenital adrenal hiperplazi, Cushing sendromu, overyal ve gonadal tümörler, polikistik over sendromu, erken adrenarş, gerçek erken puberte) dışlanmalıdır ${ }^{3,7}$. Hiperandrojenizm açısından taranmalıdır (Tablo 5). Adrenal tümör veya Cushing sendromundan şüpheleniliyorsa adrenokortikotropik hormon (ACTH) uyarı testi, serum ACTH seviyeleri ve 24 saatlik idrarda kortizol düzeylerine bakılmalıdır ${ }^{2}$. Tedavi, bu yaş grubunda öncelikle altta yatan nedene yönelik olmalıdır. Ayrıca tedavi gerekirse infantil akne tedavisine benzer şekilde yapılmalıdır ${ }^{2,3}$

\section{Preadölesan Akne}

Preadölesan akne 7-12 yaşları arasında görülen akne lezyonlarıdır (Tablo 6). Lezyonlar alın orta kısımlarında, T bölgesinde ve kulaklarda görülebilir². Lezyonlar kademeli olarak enflamatuvar papül ve püstüllere ilerleyerek yayılır. Bu yaş grubunda akne görülmesi genellikle normal ise de bazen geç başlangıçı konjenital adrenal hiperplazi veya Polikistik Over sendromu gibi altta yatan nedenlerin bir göstergesi de olabilir². Preadölesan akne, kızlarda genellikle 6-7 yaşlarında, erkeklerde 7-8 yaşlarında başlayan adrenal bezlerin fizyolojik uyanışının yansımasıdır. DHEA ve DHEA-S seviyeleri artmaya başlar ve sebase bez salgıları aktive olur. Komedonal aknesi şiddetli olan kızlarda DHEA-S düzeyleri, hafif komedonal aknesi olan veya komedonal aknesi olmayan kızlara göre daha yüksektir. Ayrıca 8 yaşından itibaren akneli çocuklarda sebum yapımındaki artışla $P$. acnes kolonizasyonu paralel olarak görülür². Puberte yaşının düşmesiyle birlikte preadölesan akne sıklığı artmaktadır. Bu yaş grubunda tedavi adölesan ve erişkin akne tedavisine benzer şekilde yapııı, tetrasiklin ve kinolonlar kullanılmamalıdır?. Hastaların resimleri için ailelerinden onam alınmıştır.

\section{Kaynaklar}

1. Paller AS, Mancini AJ: Disorders of the sebaceous and sweat glands. In: Hurwitz Clinical Pediatric Dermatology. A Textbook of Skin Disorders of Childhood and Adolescence. 5th ed. China. Elsevier Saunders, 2016;175192.

2. Maroñas-Jiménez L, Krakowski AC: Pediatric acne: Clinical patterns and pearls. Dermatol Clin 2016;34:195-202. 
3. Eichenfield LF, Krakowski AC, Piggott $C$, et al: American Acne and Rosacea Society. Evidence-based recommendations for the diagnosis and treatment of pediatric acne. Pediatrics 2013;131:S163-86.

4. Friedlander SF, Baldwin HE, Mancini AJ, Yan AC, Eichenfield LF: The acne continuum: an age-based approach to therapy. Semin Cutan Med Surg 2011;30:S6-11.
5. Admani S, Barrio VR: Evaluation and treatment of acne from infancy to preadolescence. Dermatol Ther 2013;26:462-6.

6. Yeo L, Ormerod AD: Treatment of acne in children. Am J Clin Dermatol 2014;15:77-86.

7. Que SK, Whitaker-Worth DL, Chang MW: Acne: Kids are not just little people. Clin Dermatol 2016;34:710-6. 